\title{
EXAMINATION OF VEHICLE PERFORMANCE AT HIGH SPEED AND HIGH CANT DEFICIENCY
}

\author{
Brian Marquis \\ U.S. Department of Transportation, Research and \\ Innovative Technology Administration, Volpe \\ National Transportation Systems Center \\ Cambridge, Massachusetts, United States
}

\author{
Jon LeBlanc \\ U.S. Department of Transportation, Research and \\ Innovative Technology Administration, Volpe \\ National Transportation Systems Center \\ Cambridge, Massachusetts, United States
}

\author{
Ali Tajaddini \\ U.S. Department of \\ Transportation, Federal Rail \\ Road Administration, Office of \\ Research and Development, \\ Washington D.C., United States
}

\begin{abstract}
In the US, increasing passenger speeds to improve trip time usually involves increasing speeds through curves. Increasing speeds through curves will increase the lateral force exerted on track during curving, thus requiring more intensive track maintenance to maintain safety. These issues and other performance requirements including ride quality and vehicle stability, can be addressed through careful truck design. Existing high-speed rail equipment, and in particular their bogies, are better suited to track conditions in Europe or Japan, in which premium tracks with little curvature are dedicated for high-speed service.
\end{abstract}

The Federal Railroad Administration has been conducting parametric simulation studies that examine the performance of rail vehicles at high speeds (greater than $90 \mathrm{mph}$ ) and at high cant deficiency (greater than 5 inches). The purpose of these analyses is to evaluate the performance of representative vehicle designs subject to different combinations of track geometry variations, such as short warp and alinement.

\section{INTRODUCTION}

In the US, increasing passenger speeds to improve trip time usually involves increasing speeds through curves. Increasing speeds through curves will increase the lateral force exerted on track during curving, thus requiring more intensive track maintenance to maintain safety.
The research for this paper was part of work done for the FRA to support the FRA Railroad Safety Advisory Committee (RSAC) Track Working Group's Vehicle Track Interaction (VTI) Task Force. The mission of the VTI task force was to update Parts 213 and 238 of the Code of Federal Regulations (CFR) regarding rules for high speed (above $90 \mathrm{mph}$ ) and high cant deficiency (about 5 inches) operations. The task force focused on a number of issues including refinement of VTI safety criteria, track geometry standards, vehicle qualification procedures and requirements and track inspection requirements, all with a focus on treating the vehicle and track as a system. Table 1 shows a list of the revised VTI safety criteria proposed in the Notice of Proposed Rule Making published in the Federal Register on May 10, 2010. These criteria delineate safe and unsafe vehicle response in establishing track geometry standards and during vehicle qualification. They are intended to prevent derailment, damage to the track structure, and injury of the passenger during normal operation.

\section{VEHICLE MODELS}

The objective of this study was to get an understanding of how different vehicles dynamically respond to a series of alinement, profile and combined track defects. To achieve this goal, it was important that the vehicles chosen for simulation provided a representative subset of equipment currently in operation. Two of the vehicles chosen were the Acela Powercar and the Amfleet Coach. These two vehicles provide results for 
passenger and non-passenger equipment and two different primary suspension types. The two models also provided a high degree of confidence in the results, with both being validated against measured vehicle response data.

Table 1 VTI Safety Limits

\begin{tabular}{|c|c|c|c|}
\hline \multirow[b]{2}{*}{ Parameter } & \multicolumn{2}{|c|}{ Safety Limit } & \multirow[b]{2}{*}{ Filter/Window } \\
\hline & $\begin{array}{c}\text { Passenger } \\
\text { Cars }\end{array}$ & $\begin{array}{c}\text { Other } \\
\text { Equipment }\end{array}$ & \\
\hline $\begin{array}{l}\text { Carbody Lateral } \\
\text { Acceleration } \\
\text { (Transient) }\end{array}$ & $\begin{array}{l}\leq 0.65 \mathrm{~g} \\
\mathrm{P}-\mathrm{P}^{1}\end{array}$ & $\begin{array}{l}\leq 0.75 \mathrm{~g} \\
\mathrm{P}-\mathrm{P}^{1}\end{array}$ & $1 \mathrm{sec}$ window \\
\hline $\begin{array}{c}\text { Carbody Lateral } \\
\text { Acceleration } \\
\text { (Sustained Oscillatory) }\end{array}$ & $\begin{array}{l}\leq 0.10 \mathrm{~g} \\
\mathrm{RMS}_{\mathrm{t}}^{2}\end{array}$ & $\begin{array}{l}\leq 0.12 \mathrm{~g} \\
\mathrm{RMS}_{\mathrm{t}}^{2}\end{array}$ & $\begin{array}{c}4 \text { sec window } \\
4 \text { sec } \\
\text { sustained }\end{array}$ \\
\hline $\begin{array}{c}\text { Carbody Vertical } \\
\text { Acceleration } \\
\text { (Transient) }\end{array}$ & \multicolumn{2}{|c|}{$\leq 1.0 \mathrm{~g} \mathrm{P}-\mathrm{P}^{1}$} & $1 \mathrm{sec}$ window \\
\hline $\begin{array}{c}\text { Carbody Vertical } \\
\text { Acceleration } \\
\text { (Sustained Oscillatory) }\end{array}$ & \multicolumn{2}{|c|}{$\leq 0.25 \mathrm{~g} \mathrm{RMS}_{\mathrm{t}}^{2}$} & $\begin{array}{c}4 \text { sec window } \\
4 \text { sec } \\
\text { sustained }\end{array}$ \\
\hline $\begin{array}{c}\text { Truck Lateral } \\
\text { Acceleration } \\
\text { (Sustained Oscillatory) }\end{array}$ & \multicolumn{2}{|c|}{$\leq 0.30 \mathrm{gRMS}_{\mathrm{t}}^{2}$} & $\begin{array}{c}2 \text { sec window } \\
2 \text { sec } \\
\text { sustained }\end{array}$ \\
\hline $\begin{array}{c}\text { Single Wheel Vertical } \\
\text { Load Ratio }\end{array}$ & \multicolumn{2}{|c|}{$\geq 0.15$} & 5 foot window \\
\hline Single Wheel L/V & \multicolumn{2}{|c|}{$\leq{\frac{\tan (\delta)-0.5^{3}}{1+0.5 \tan (\delta)}}^{3}$} & 5 foot window \\
\hline Net Axle L/V & \multicolumn{2}{|c|}{$\leq 0.4+\frac{5.0}{V a}^{4}$} & 5 foot window \\
\hline Truck-side L/V & \multicolumn{2}{|c|}{$\leq 0.60$} & 5 foot window \\
\hline
\end{tabular}

${ }^{1}$ Peak to peak value

${ }^{2}$ Root mean squared with linear trend removed

${ }^{3} \delta$ - Flange angle in radians

${ }^{4} \mathrm{Va}-$ Vertical axle load in kips

The Acela Powercar is a high-speed locomotive first qualified for use in the United States in 2000. Its maximum operational speed is $150 \mathrm{mph}$ and it is authorized to run at cant deficiencies of up to 7 inches. The locomotive has bolsterless trucks with a coil spring secondary suspension and radial arm/coil spring primary. The total vehicle weight is 200,200 pounds. The Amfleet Coach is a passenger vehicle first approved for use in the United States circa late 1970s. It is operates at speeds of up to $125 \mathrm{mph}$ at cant deficiencies of up to 5 inches. The coach has a bolstered split-frame truck with a coil spring secondary suspension. The vehicle has a total weight of 119,400 pounds.

These two vehicles were modeled using the NUCARS $\AA$ software package. This allowed for the use of advanced connection features such as non-linear elements, multiple endpoint connections, friction elements and the modeling of the longitudinal/vertical coupling seen in the radial arm primary suspension of the Acela Powercar. The NUCARS $\AA$ model of the Acela Powercar contained 19 bodies, with 109 different connections. The bodies included in the model were the carbody, leading and trailing trucks, four traction motors, eight radial arms and the four axles. The model of the Amfleet Coach consisted of 11 bodies and 116 connections. Included in the list of bodies were the carbody, the leading and trailing bolsters, the left and right frame for the leading truck, the left and right frame for the trailing truck and the four axles. The same wheel and rail profiles were used for both vehicle models. The wheels were the Amtrak Standard, using a 1 in 40 taper, 72.5 degree flange angle and a back to back spacing of 53.1875 inches. The rails were a 140 pound rail, with a 1 in 40 cant and a standard gage of 56.5 inches.

\section{SIMULATION CASES}

To gain a proper understanding of each vehicle's behavior, a matrix of track scenarios was created. For these track scenarios, two of the primary variables examined that affect vehicle response are vehicle speed and cant deficiency. Since this study was done in conjunction with the modification of the track geometry limits for different classes of track, it was determined that the speeds should be varied according to the class speeds. For Classes 4 through 7 this meant four different speed ranges, 61-80mph for Class 4, 81-90mph for Class 5, 91$110 \mathrm{mph}$ for Class 6 and 111-125mph for Class 7. In addition, it was desired to examine vehicles performance at cant deficiencies ranging for 5 inches up to 9 inches. Cant deficiency $\left(E_{a}\right)$ is calculated according to the formula shown in equation (1).

$$
\text { (1) } E_{a}=0.0007 \cdot D \cdot V^{2}-E_{u}
$$

The variables in this equation are the track curvature in degrees (D), the vehicle speed in miles per hour (V) and the track superelevation in inches $\left(\mathrm{E}_{\mathrm{u}}\right)$. For these analyses, the superelevation was fixed at a design value of 6 inches, a typical maximum value for US operation. For the superelevation chosen, two methods were available to vary the cant deficiency for any given class of track. Either the vehicle speed could either be held constant with variable track curvature, or the track curvature could be held constant with the vehicle speed varied within the specified range for the particular track class. In order to examine vehicle response in the most severe conditions, an analysis was conducted determining that setting the speed constant at the maximum class speed and varying the curvature represented the most severe case (see appendix A). This determination was performed for class 8 track and may not hold for lower classes of track where curvature becomes very large to produce comparable levels of cant deficiency. A list of the different track speeds and curvatures is shown in Table 2 . 
TABLE 2 DEGREE OF CURVATURE

\begin{tabular}{|c|c|c|c|c|c|}
\hline & \multicolumn{4}{|c|}{ Vehicle Speed (mph) } \\
\hline & & 80 & 90 & 110 & 125 \\
\hline \multirow{3}{*}{ 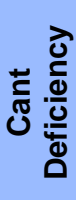 } & 5" & 2.46 & 1.94 & 1.30 & 1.01 \\
\hline & 7" & 2.90 & 2.29 & 1.53 & 1.19 \\
\hline & 9" & 3.35 & 2.65 & 1.77 & 1.37 \\
\hline
\end{tabular}

Along with the vehicle speed and cant deficiency, the perturbation wavelength was also varied. The three chosen wavelengths were 31,62 and 124 feet, to conform to the MCO wavelengths found in the FRA track geometry. The shape of the perturbation for all three wavelengths was a sinusoidal "bump," where the amplitude was at zero at the beginning of the wavelength, at its peak in the middle and returned to zero at the end. A sinusoidal "step" was also initially examined, where the amplitude was zero at the beginning, half in the middle and at its peak at the end, remaining at the value for duration of the run. The results presented in this paper are for the "bump" case only.

The combination of speed, cant deficiency and perturbation wavelength variations created 36 sets of runs for each vehicle. For each of these sets a matrix of alinement and profile amplitudes was chosen to study the vehicle's response to various perturbations. In addition to examining alinement or profile alone defects, combination defects were also analyzed. For the combination cases, the alinement and profile perturbations were placed at the same track location. The effect of mixing two different wavelengths for a combination defect was not studied.

Perturbation amplitudes ranged from -2 to 2 inches for alinement -2.5 to 2.5 inches for profile. A negative value for alinement signified an inward (gage narrowing) defect and a dip (downward) defect for profile. Perturbations were placed on the high rail in the curve and conditionally on the low rail to maintain the FRA gage and cross-level limits. The amplitudes for alinement or profile alone perturbations were incremented by 0.1 inches and the combination perturbation were incremented by 0.2 inches. This led to a total of 571 simulations needed to complete a given speed/cant deficiency/wavelength set.

\section{RESULTS}

The data was organized in order to establish limits on track geometry. For each case, the data channels produced included the information needed to compare to the VTI criteria listed in Table 1, axle displacements, track deflections along with other information useful for analyzing and validating the results. From all of this data, the goal was to locate and record the peak, or controlling, value for each of the safety criteria.
The data for the various safety criteria were filtered and processed. Wheel force criteria were processed through a $25 \mathrm{~Hz}$ lowpass filter and acceleration criteria were processed through a $10 \mathrm{~Hz}$ lowpass filter. In addition to this frequency based filtering, additional time and distance based windows were used as described in Table 1. The final step in the process was to locate a record the controlling value for each safety criteria based on all of the wheels, axles, trucks or carbody locations.

Figure 1 shows example time histories typical Net Axle L/V (NAL) responses for the Acela Powercar. The results plotted here are for axle 2 alone, as it produced the controlling value for each of the different alinement amplitudes in the figure. Plotted along with the NAL results are the NAL safety limit and the alinement deviation location and geometry. The two markers on the 1.5 inch results denote the start and end of the 5 foot window containing the maximum NAL value in accordance with the VTI safety criteria. So while the 1.5 inch response does exceed the limit for NAL, it does not exceed it for a length of 5 feet. The minimum amplitude within 5 feet (as labeled in the figure) is the value that is subject to the limits shown in Table 1. This was the one value stored for NAL for each simulation, with a similar process done for each of the other VTI limits. So, for each individual simulation, 9 points of data were stored.

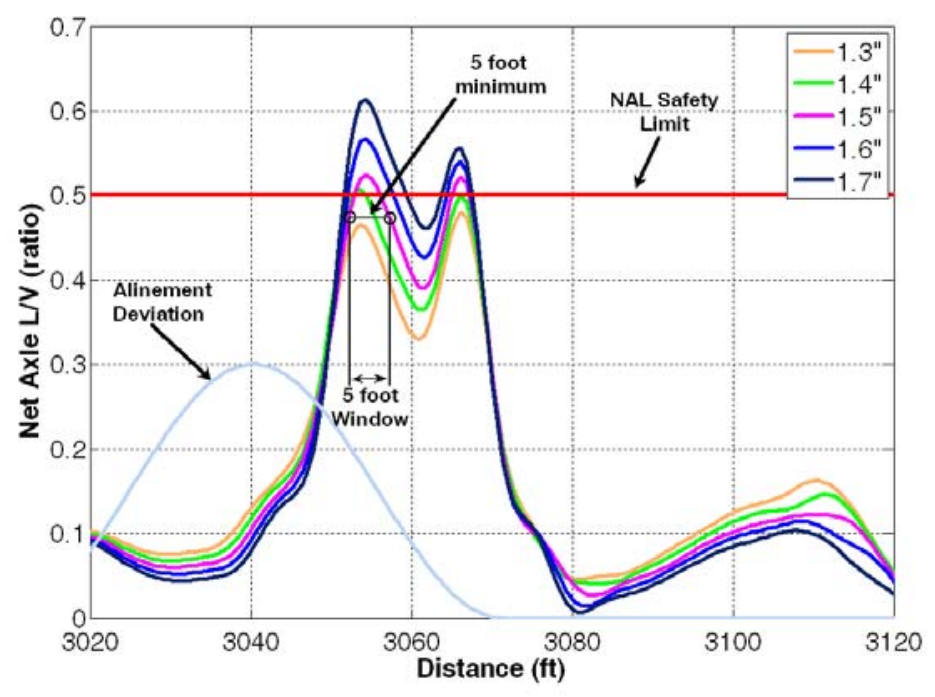

Figure 1 Acela Powercar, Class 7 (125mph), 62 foot chord at 7 inches of cant deficiency

The next step in the data reduction was to calculate these limiting criteria values for each simulation in a given speed/cant deficiency/wavelength set. From this larger set of data, trends of safety criteria versus alinement or profile amplitude could be derived. Limits for perturbation amplitudes 


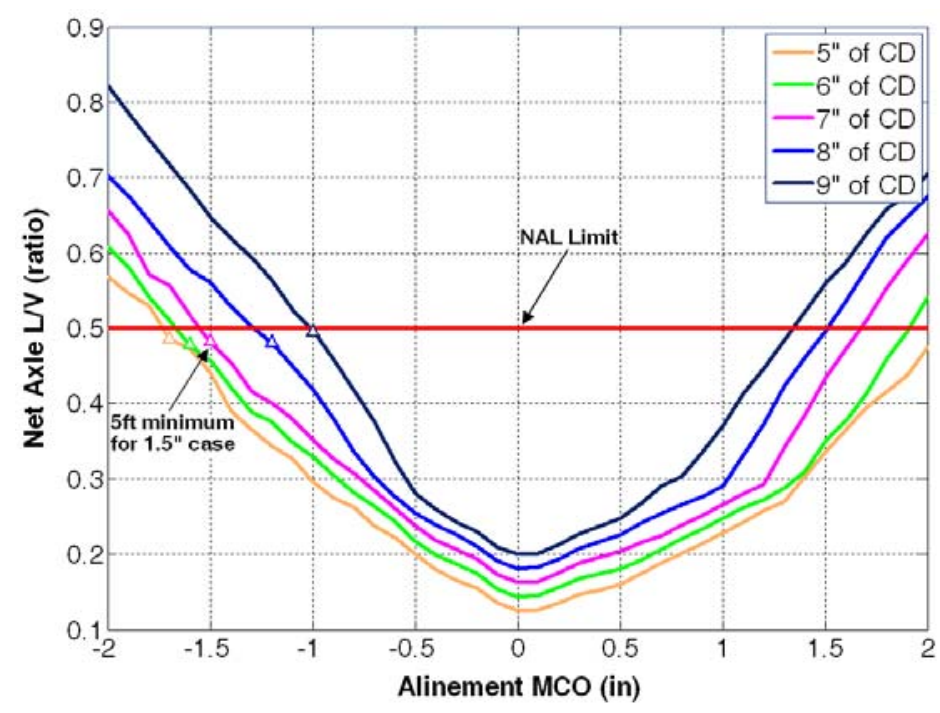

Figure 2 Acela Powercar, Class 7 (125mph) 62 foot chord

were found through comparing the list of controlling criteria values at various amplitudes to the limits shown in Table 1 . The NAL limit is the dark horizontal line plotted here. Amplitude limits were defined as the last value before the criteria was exceeded. The plot shown in Figure 2 displays examples of a NAL versus alinement amplitude results. The value pointed to along the 7 inch cant deficiency line, is the same maximum value pointed to in Figure 1. The triangular markers in the figure denote the limiting alinement for each different cant deficiency. It can be seen that the magnitude of the NAL response increases with cant deficiency as well as alinement amplitude. Each line for a higher cant deficiency falls entirely above those for lower cant deficiencies. This plot shows that at higher cant deficiency the margin of safety is smaller (with no perturbation) and that the response to geometry perturbations is more severe (slope of lines is higher). The limiting amplitudes all occur for negative perturbations (inward) and vary from 1.7 inches at 5 inches of cant deficiency down to 1.0 inch at 9 inches of cant deficiency. From each full set of simulations only these amplitude limits were recorded. So, for each set of simulations, the number of data points was reduced to 18 , the alinement and profile limits (if reached) for each of the 9 VTI safety criteria.

Results were further condensed to examine trends with speed and cant deficiency for alinement and surface limits alone. Figure 3 shows the alinement limits for selected criteria for the Acela Powercar. The value pointed to in Figures 1 and 2 is labeled here again, shown here for the Class 7, 62 foot limits. The controlling limit for each case is included in this figure. The dashed vertical lines separate the different classes with the cant deficiencies increasing from left to right. The solid line without markers display the proposed track geometry limits. It can be seen that for the majority of cases, the allowable alinement values decrease as cant deficiency increases. Another interesting aspect is that the allowable amplitudes are higher at high speed and low cant deficiency than they are at low speed and high cant deficiency. For example, the limit found using carbody lateral peak-to-peak acceleration for the 62 foot wavelength for Class 6 at 9 inches of cant deficiency is
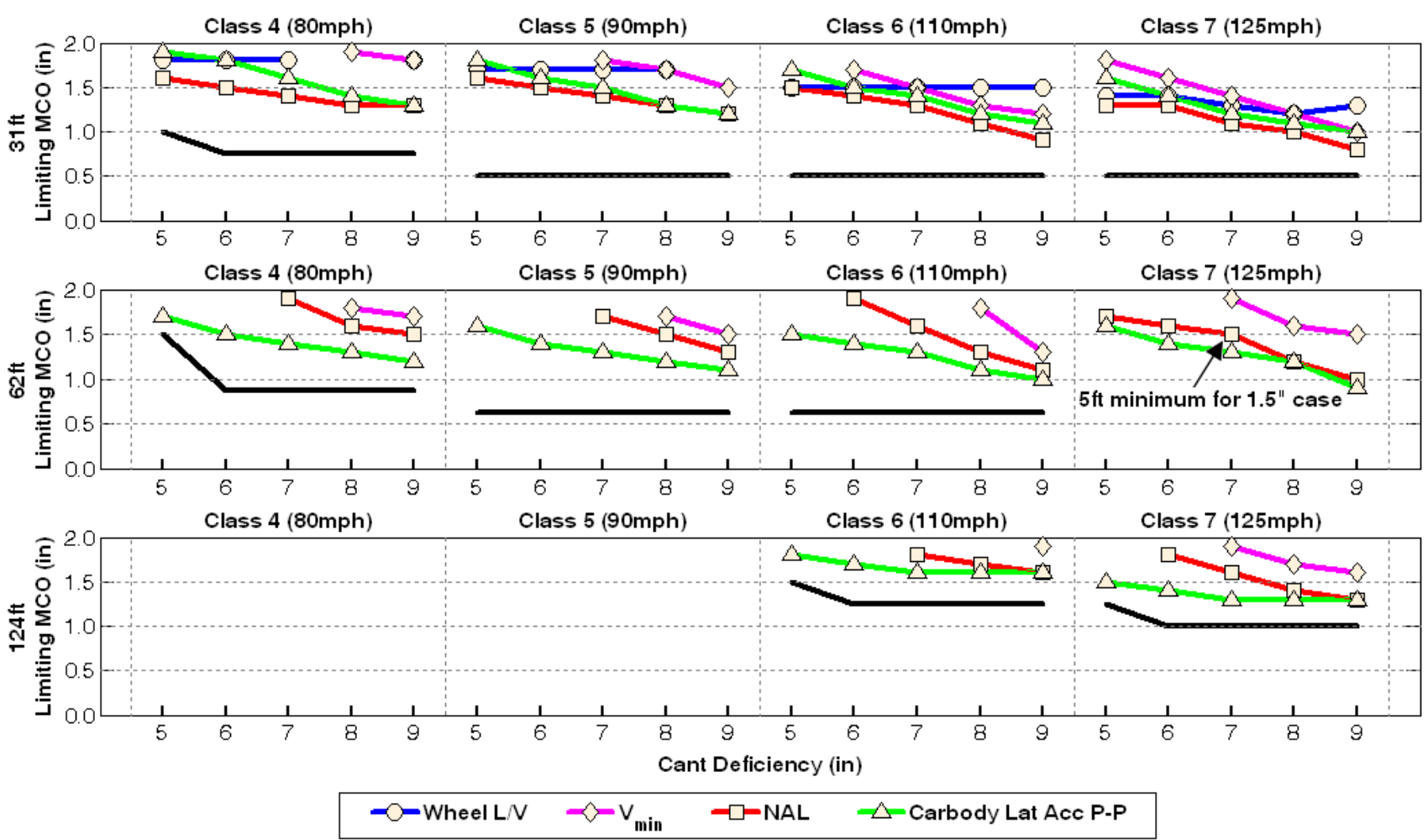

Figure 3 Acela Powercar isolated alinement perturbation 
shown to be 1 inch. For Class 7 at 5 inches of cant deficiency, the limit increases to 1.6 inches. That is a $15 \mathrm{mph}$ increase in speed, but an additional 0.6 inches permissible in a track perturbation. These results emphasize that the operation at higher cant deficiencies can be more of a safety concern than the operation at higher speeds.

An additional set of plots was developed to look at the effect of combined defects. Because the amplitude of these perturbations had more than one variable, it was not possible to create a succinct set of summary plots as shown in Figure 3. Instead of plotting the data for each criteria, a two-dimensional summary map was created. The map was made up of squares, each representing a possible combination of alinement and profile. If any one or multiple criteria were exceeded for a given combination, the squared was shaded, otherwise it remained blank. Figures 4 though 6 summary maps for all of the Acela Powercar and Amfleet Coach results.

As with the isolated defect results, it can be seen that instances of lower speed and higher cant deficiency produce more shaded regions than higher speed at lower cant deficiency. In Figure 5, the Class 5, 9 inch cant deficiency case for the Acela Powercar is more restrictive in many regions than the Class 7, 5 inch cant deficiency case. A common trend can also be seen in all of these figures. Squares in quadrants 1 and 3 have more shading than those in quadrants 2 and 4 . This indicates that down and out or up and in combined defects are those of greatest concern.

\section{SUMMARY}

With the increased demand to operate at high speeds and high cant deficiencies, it is important to understand the requirements of track and equipment for operating safely under these conditions. The results presented in this paper examine the effect of speed and cant deficiency on vehicle response and track requirements. The results of this study show that existing vehicle designs, currently operated in the US, have tighter track geometry requirements when operated at high cant deficiency than when the same equipment is operated at higher speeds. Further research is required to understand how trucks can be designed to improve performance of vehicles at high cant deficiency. The FRA is currently funding a study into the design of a high speed, high cant deficiency truck and will be reported in future papers.

\section{ACKNOWLEDGEMENTS}

This work was sponsored by the FRA Office of Research and Development, Track Research Program.

\section{REFERENCES}

US Department of Transportation, FRA, "49 CFR Parts 213 and 238 - Vehicle/Track Interaction Safety Standards; HighSpeed and High Cant Deficiency Operations; Proposed Rule," Federal Register May 10, 2010

Klauser, P., Wilson, N., Dembosky, M., 2010 Users Manual for NUCARS Version 2010.1, Association of American Railroads 


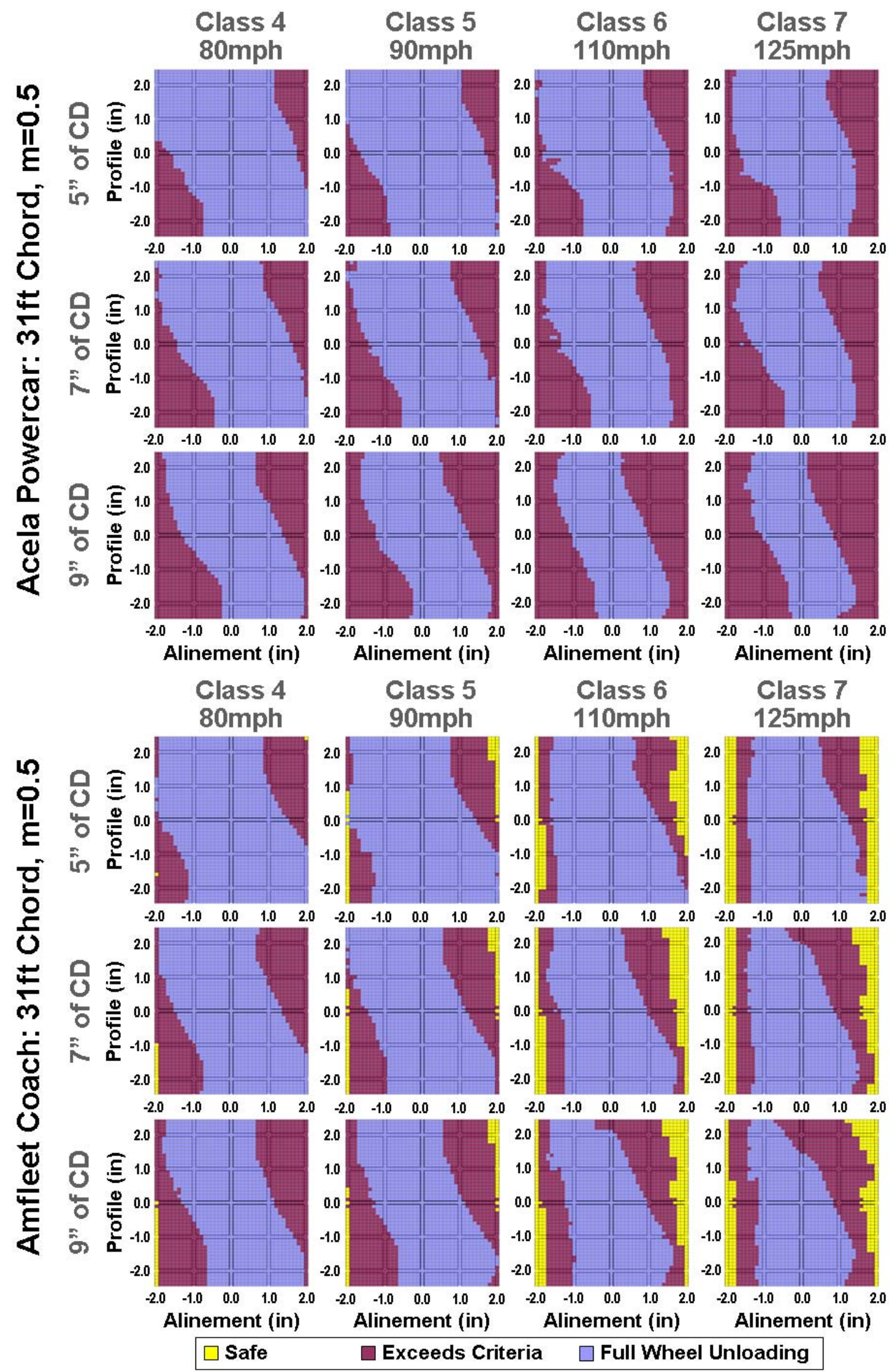

Figure 4 Acela Powercar and Amfleet Coach 31 foot wavelength combined results 


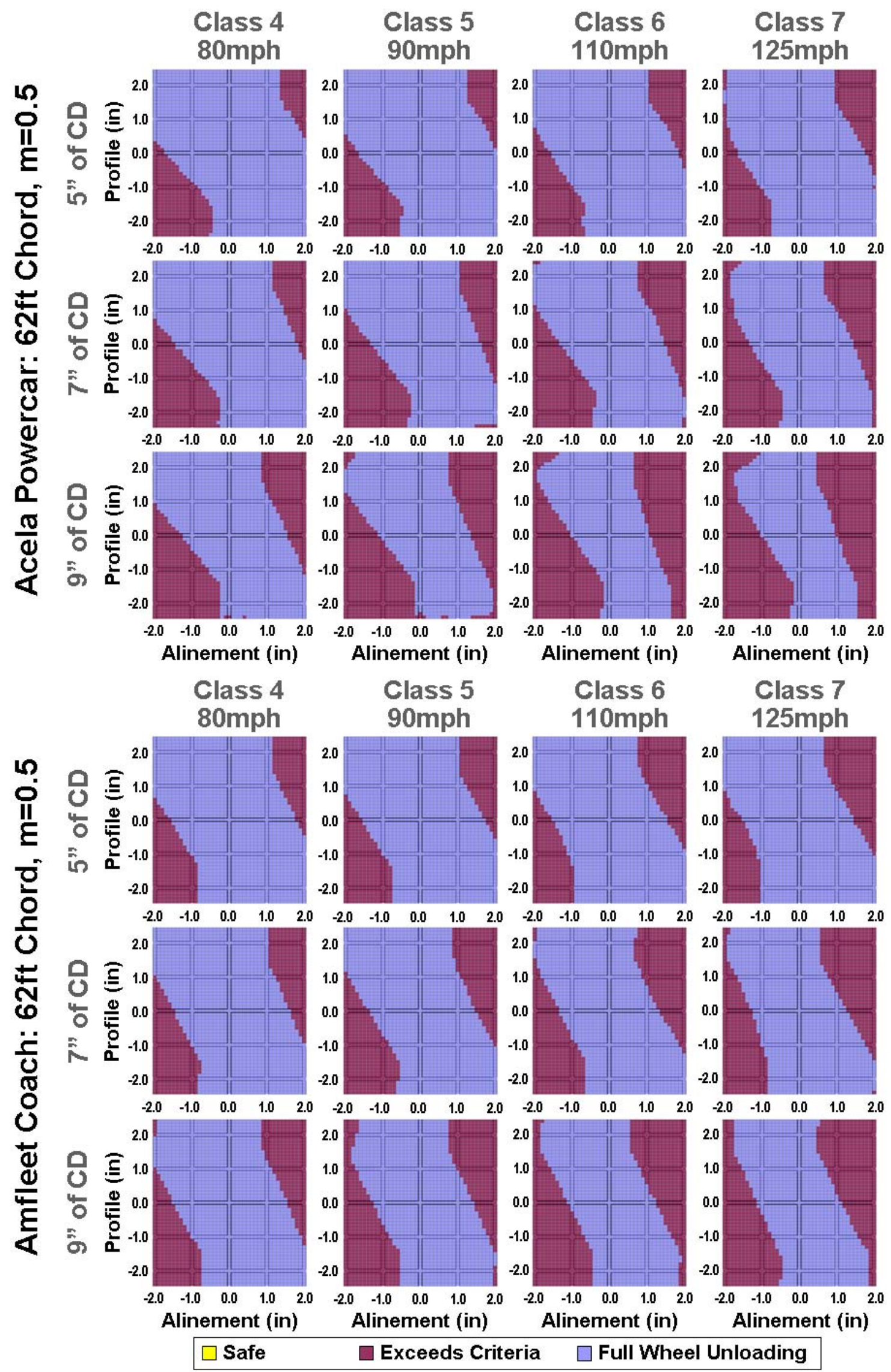

Figure 5 Acela Powercar and Amfleet Coach 62 foot wavelength combined results 


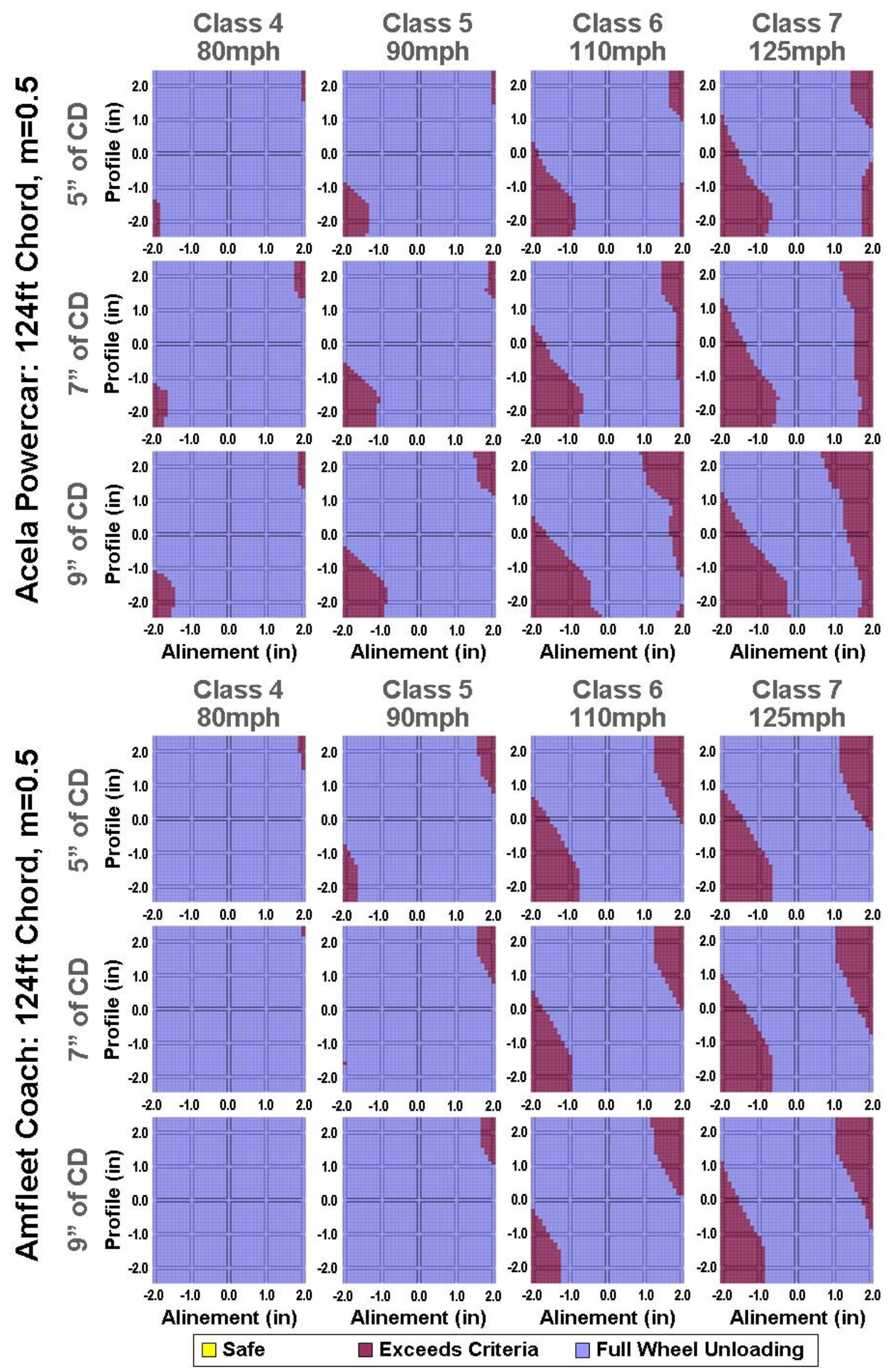

Figure 6 Acela Powercar and Amfleet Coach 124 foot wavelength combined results 

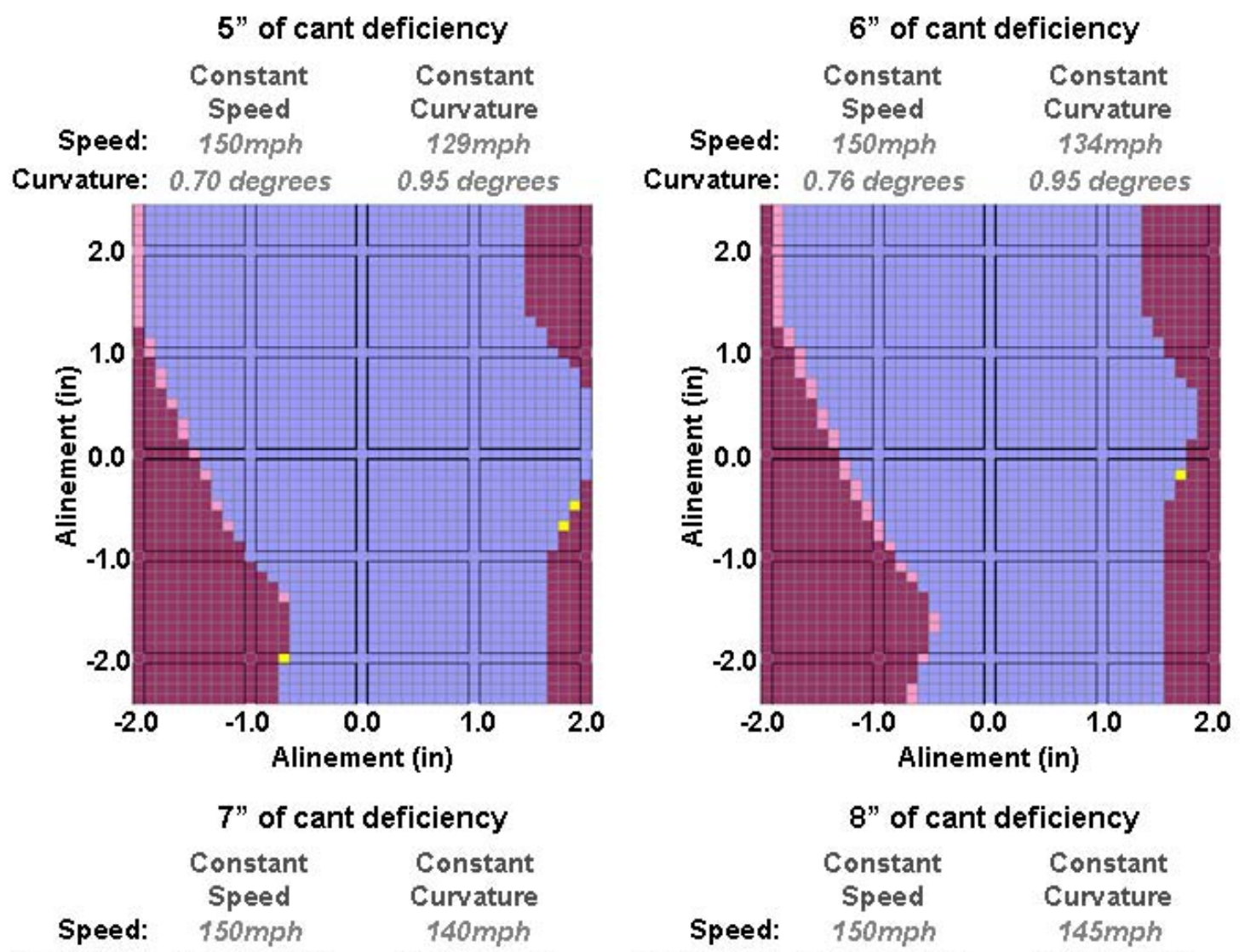

Curvature: 0.83 degrees 0.95 degrees

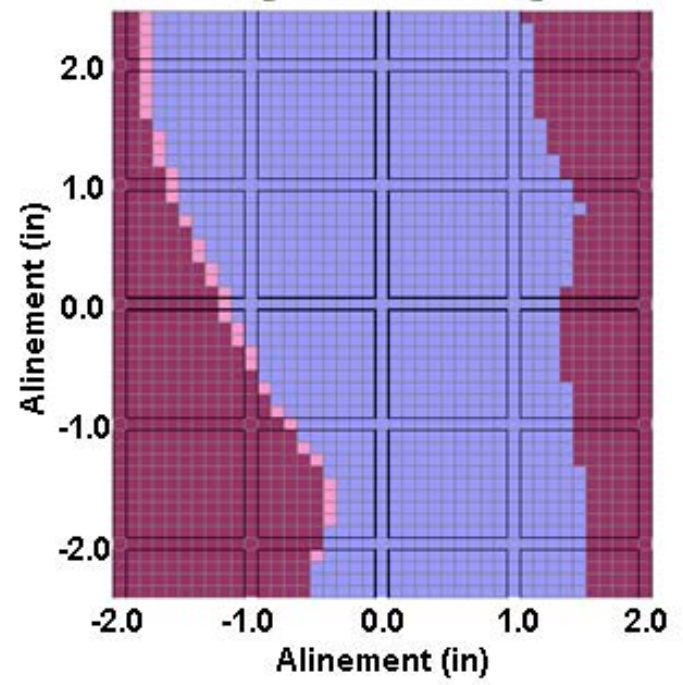

Curvature: 0.89 degrees 0.95 degrees

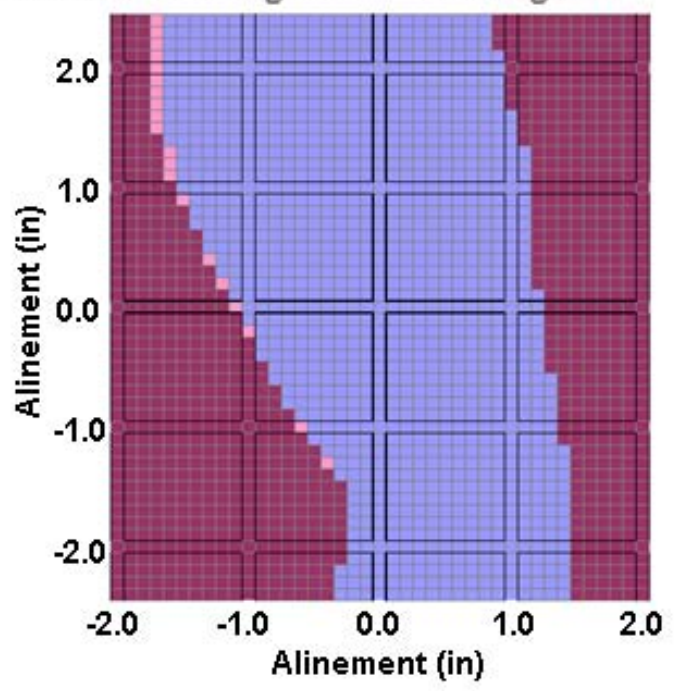

$\square$ Safe
$\square$ Exceeds Criteria for Both
$\square$ Exceeds Criteria for Constant Speed
$\square$ Exceeds Criteria for Constant Curvature

Results for the Acela Powercar, Class 8, 124 foot wavelength 